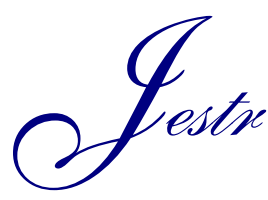

Research Article

MIMMM iectr nro

\title{
Performance Analysis of AODV, DSR and ZRP in MANETs using QualNet Simulator
}

\author{
N. Arora* \\ Department of Computer Science \& Engineering, G. B. Pant Engineering College, Uttarakhand, India
}

Received 3 April 2012; Accepted 15 January 2013

\begin{abstract}
A Mobile Ad-Hoc Network (MANET) is a collection of wireless mobile nodes forming a temporary network without using any centralized access point, infrastructure, or centralized administration of the mobile networks. Data transmission between two nodes requires multiple hops as nodes transmission range is limited in Mobile Ad hoc networks (MANET's). Mobility of the networks nodes to makes the situation even more complicated in wireless networks. Multiple routing protocols find optimized routes from a source to some destination. This articles presents performance analysis of three different routing protocols AODV, DSR and ZRP for Mobile Ad-Hoc networks (MANET's). In this paper we have used QualNet Simulator 5.0.2 from Scalable Networks to perform the simulations. Performance analysis of AODV, DSR and ZRP is evaluated based on Average Jitters(s), Average end to end delay(s), Throughput(bps) and TTL based hop count in Mobile ad hoc networks.
\end{abstract}

Keywords: Routing Protocols; Average end to end delay; TTL; Average Jitters; Throughput; AODV; DSR; ZRP; MANET.

\section{Introduction}

A mobile ad hoc network (MANET) [1] group has been formed within IETF. The goal is to support mobile ad hoc networks with hundreds of routers and solve challenges. A mobile ad hoc network (MANET) is a self-configuring infrastructure less network of mobile devices connected by wireless links. Each device in a MANET is free to move independently in any direction, and will therefore change its links to other devices frequently. An ad hoc network is a collection of mobile computers or mobile nodes that cooperate to forward packets for each other to extend the limited transmission range of each node's wireless network interface. Each must forward traffic unrelated to its own use, and therefore be a router. Wireless networks are an emerging new technology that will allow users to access information and services electronically, regardless of their geographic position. Wireless networks can be classified in two type's infrastructure network and infrastructure less (ad hoc) networks. Infrastructures network consists of a network with fixed and wired gateways. A mobile host communicates with a bridge in the Network or called base station within its communication radius. The mobile unit can move geographically while it is communicating. When it goes out of range of one base station, it connects with new base station and starts communicating through it. The primary challenge in building a MANET is equipping each device to continuously maintain the information required to properly route traffic. Such networks may operate by themselves or may be connected to the larger Internet. Active research work for mobile ad hoc networks is carrying on mainly in the fields of Medium Access Control (MAC), routing, resource management, power control, and security. Because of the importance of routing protocols in dynamic multi hop networks, a lot of mobile ad hoc network routing protocols have been proposed in the last few years. Mobile ad hoc networks originated from the DARPA (PRNet) [2] and SURAN project [2].

The remainder of this paper is organized as follows. Section 2 introduces MANETs routing protocols. Section 3 describes the overview of different Routing Protocols in Mobile Ad hoc Networks (MANET), Parameters for Simulation Setup in section 4, Section 5 shows the Node Placement Scenarios, Animation view in Section 6, Simulation results of AODV, DSR and ZRP Protocols in Section 7 and Conclusion in Section 8.

\section{Mobile Ad-Hoc Networks (MANET)}

In Ad hoc networks, nodes do not have a prior knowledge of topology of network around them, they have to discover it. The basic idea is that a new node (optionally) announces its presence and listens to broadcast announcements from its neighbors. The node learns about new near nodes and ways to reach them, and may announce that it can also reach those nodes. As time goes on, each node knows about all other nodes and one or more ways how to reach them. Routing Protocols can be divided into two categories based on when and how the routes are discovered.

- Pro-active Routing or table driven Protocols.

- Reactive Routing or On-demand routing Protocols.
*E-mail address: nitinarora47@gmail.com

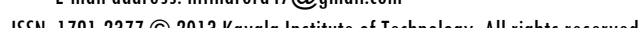


- Hybrid (Pro-active/Reactive).

In pro-active or table driven routing protocols each node maintains one or more tables containing routing information to every other node in network. All nodes update these tables so as to maintain a consistent and up-to-date view of the network. When the network topology changes the nodes propagate update messages throughout the network in order to maintain consistent and up-to-date routing information about the whole network. These routing protocols differ in method by which the topology change information is distributed across the network and the number of necessary routing-related tables.

Unlike pro-active, Reactive or On-demand routing protocols take a lazy approach to routing. In contrast to Proactive Routing protocols all up-to-date routes are not maintained at every node, instead the routes are created as and when needed. When a source wants to send to a destination, it invokes the route discovery mechanism to find the path to the destination. The route remains valid till the destination is reachable or until the route is no longer needed. Protocols such as DSR [3,4] and AODV[5] are members of the re-active protocol class.

Hybrid protocols combine the advantages of pro-active and reactive routing. The routing is initially established with some pro-actively prospected routes and then serves the demand from additionally activated nodes through reactive flooding. The ZRP $[6,7,8]$ is an example of a hybrid routing protocol.

\section{Overview of Routing Protocols in Mobile ADHoc Networks (MANET)}

\subsection{The dynamic source routing (DSR) protocol}

The dynamic source routing protocol (DSR) $[3,4]$ is an on demand routing protocol. DSR is simple and efficient routing protocol designed specifically for use in multi-hop wireless ad hoc networks of mobile nodes. Using DSR the network is completely self-organizing and self-configuring requiring no existing network infrastructure or administration. The DSR protocol is composed of two main mechanisms that work together to allow the discovery and maintenance of source route in the ad hoc network.

- Route discovery: Route discovery is the mechanism by which a node $\mathrm{S}$ wishing to send a packet to a destination node D obtains a source route to D Route discovery is used only when $\mathrm{S}$ attempts to sent a packet to $\mathrm{D}$ and does not already know a route to $\mathrm{D}$.

- Route maintenance: Route maintenance is the mechanism by which node $S$ is able to detect .while using a source route to $\mathrm{D}$ if the network topology has changed such that it can no longer use it route to D because a link along the route no longer works. When route maintenance indicates a source route is broken. S can attempts to use any other route it happens to know to $\mathrm{D}$ or it can invoke route discovery again to find a new route for subsequent packets to $\mathrm{D}$. route maintenance for this route is used only when $\mathrm{S}$ is actually sending packets to $\mathrm{D}$.

\subsection{The Ad Hoc On-demand Distance Vector Routing (AODV) protocol}

Reactive routing protocol AODV [5] only needs to maintain the routing information about the active paths. Routing information is maintained in routing tables at nodes. Every mobile node keeps a next-hop routing table, which contains the destinations to which it currently has a route. A routing table entry expires if it has not been used or reactivated for a pre-specified expiration time. Moreover, AODV adopts the destination sequence number technique used by DSDV in an on-demand way. In AODV, when a source node wants to send packets to the destination but no route is available, it initiates a route discovery operation. In the route discovery operation, the source broadcasts route request (RREQ) packets. A RREQ includes addresses of the source and the destination, the broadcast ID, which is used as its identifier, the last seen sequence number of the destination as well as the source node's sequence number. Sequence numbers are important to ensure loop-free and up-to-date routes. To reduce the flooding overhead, a node discards RREQs that it has seen before and the expanding ring search algorithm is used in route discovery operation. The RREQ starts with a small TTL (Time-To-Live) value. If the destination is not found, the TTL is increased in following RREQs.

\subsection{Zone Routing Protocol (ZRP)}

Zone Routing Protocol (ZRP) [6, 7, 8] combines the advantages of both reactive and pro-active protocols into a Hybrid scheme, taking advantage of pro-active discovery within a node's local neighborhood, and using a reactive Protocol for communication between these neighborhoods. In a MANET, it can safely be assumed that the most Communication takes place between nodes close to each other. The ZRP is not so much a distinct protocol as it provides a framework for other protocols. The separation of a nodes local neighborhood from the global topology of the entire network allows for applying different approaches and thus taking advantage of each technique's features for a given situation. These local neighborhoods are called zones each node may be within multiple overlapping zones, and each zone may be of a different size. The "size" of a zone is not determined by geographical measurement, but is given by a radius of length, where is the number of hops to the perimeter of the zone. By dividing the network into overlapping, variable-size zones, the Zone Routing Protocol consists of several components, which only together provide the full routing benefit to ZRP. Each component works independently of the other and they may use different technologies in order to maximize efficiency in their particular area. Components of ZRP are IARP, IERP and BRP.

\section{Parameters for Simulation Setup}

In this work Qualnet 5.0.2 network simulator [9] has been used to evaluate the performance of AODV, DSR and ZRP protocols of mobile ad-hoc networks. Table 1 describes the different parameters used for the simulation setup for Qualnet Simulator 5.0.2

Tables 1. Parameters for simulation setup scenarios

\begin{tabular}{l|l}
\multicolumn{1}{c|}{ Parameters } & \multicolumn{1}{c}{ Values } \\
\hline No. of Nodes & 20 \\
Area & $700 \mathrm{~m} * 700 \mathrm{~m}$ \\
Routing Protocols & AODV, DSR and ZRP \\
Fading Model & Rayleigh \\
Shadowing Model & Constant \\
Energy Model & Mica Motes \\
Battery Model & Simple linear \\
Terrain File & DEM
\end{tabular}




\begin{tabular}{l|l}
\hline Node Placement & Random node placement \\
Simulation time & $120 \mathrm{sec}$ \\
Channel frequency & $2.4 \mathrm{Ghz}$ \\
Traffic Source & $\mathrm{CBR}$ \\
\hline
\end{tabular}

\section{Nodes Placement Scenarios}

Figure 1 shows the node placement scenarios for the routing protocols.

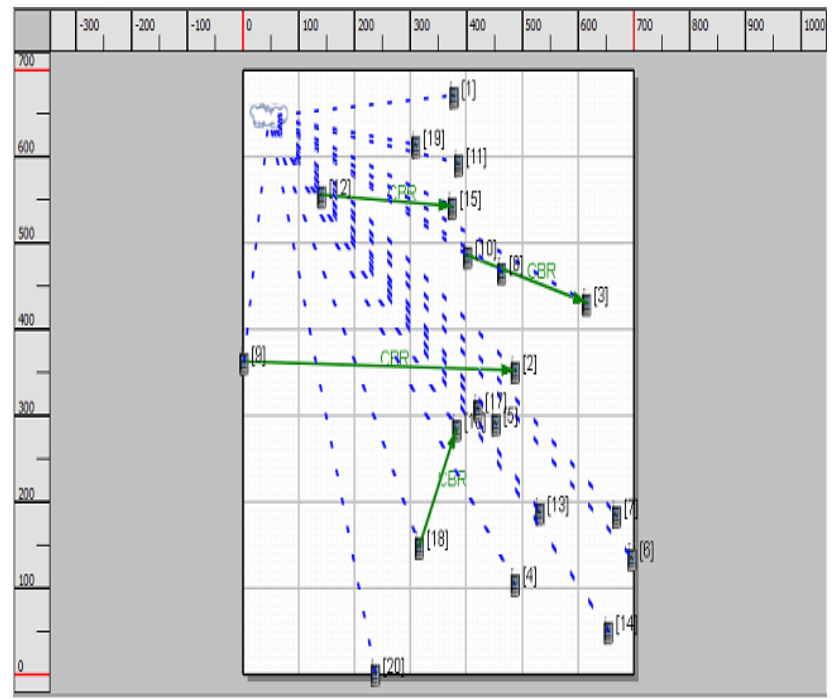

Fig.1. Node Placement Scenarios

\section{ANIMATION VIEW OF SCENARIOS}

Figure 2 shows the animation view of scenarios for the routing protocols.

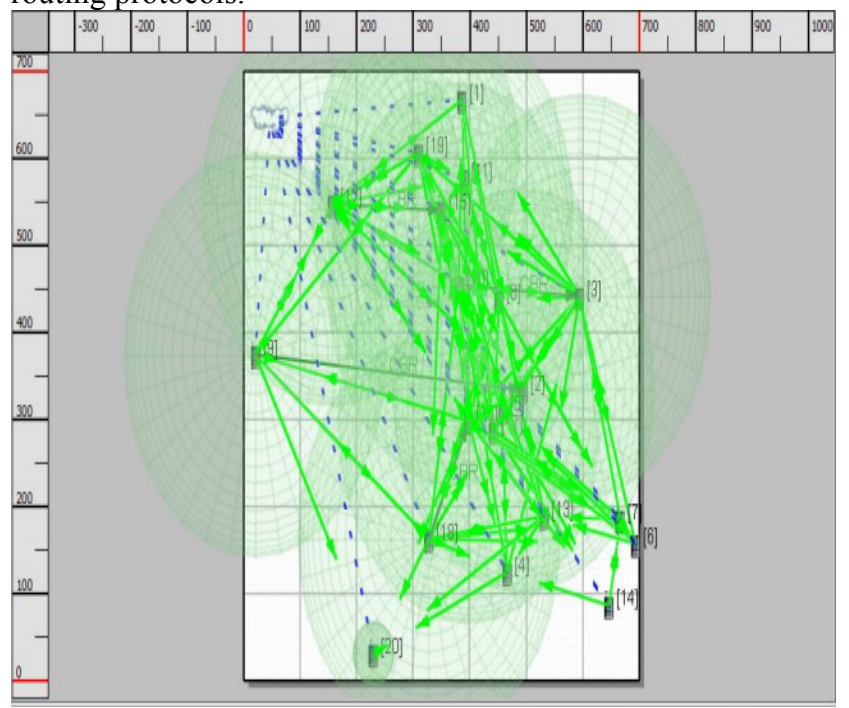

Fig. 2. Animation view of scenarios

\section{Simulation Results of AODV, DSR and ZRP Protocols}

\subsection{Average Jitter}

The variation of average jitter of various routing protocols with respect to node density 20 nodes is given in figure 3. AODV shows the least average jitter in 20 nodes scenarios for mobile ad-hoc network as compared to other protocols. This is because AODV is a proactive routing protocol which contains the route information in its routing table this reduces the search for new routes.

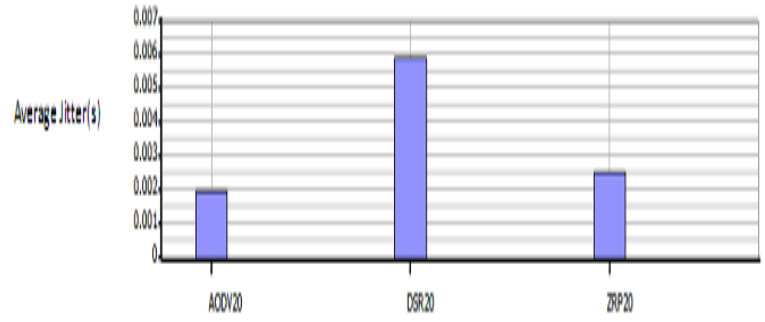

Fig. 3. Average Jitter(s) Vs Nodes of Protocols

\subsection{Average End to End delay}

Figure 4 shows the variation in end-to-end delay with respect to node density 20 .

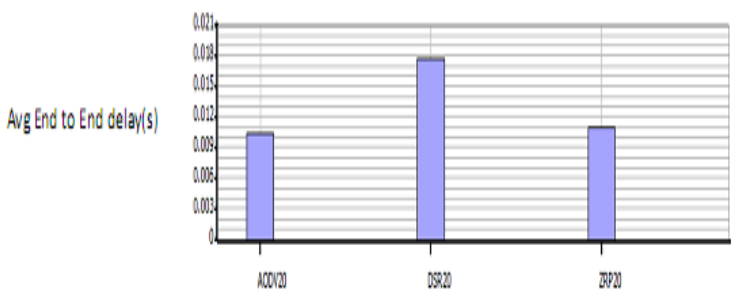

Fig 4. Average End to End delay(s) Vs Nodes of Protocols

\subsection{Throughput}

The variation of throughput of various routing protocols with respect to node density 20 nodes is given in figure 5 . The throughput for AODV, DSR and ZRP protocols is almost same (around 4000bps).

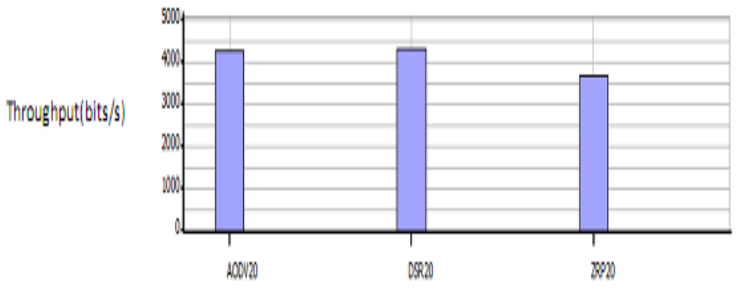

Fig 5. Throughput (bits/s) Vs Nodes of Protocols

\subsection{TTL based Hop count}

Figure 6 shows the variation in TTL based hop count with respect to node density 20 .

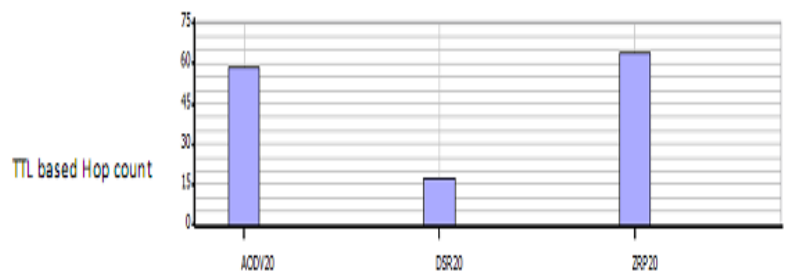

Fig 6. TTL based Hop count Vs Nodes of Protocols

\section{Conclusion}

This article mainly focuses on proactive, reactive, and hybrids routing protocols like AODV, DSR, and ZRP. We have analysis performance of these routing protocols on the basis of Performance Matrices Average Jitters, Average End to End delay(s), Throughput (bits/s) and TTL based Hop count using Qualnet 5.0.2 network simulator. These performances taken according to apply constant bit rate 
(CBR) of nodes from source to destination. All the CBR starting time $1 \mathrm{sec}$ from source and $25 \mathrm{sec}$ end from the destination nodes of CBR All simulation time of the scenario's $120 \mathrm{sec}$ to complete of the process. From the result it can be observed that AODV and DSR are suited for application where average jitter and throughput are very critical. ZRP being the location based protocol need sufficient time to establish route discovery and route maintenance: hence for large range mobile application they are best suited.

\section{References}

1. C.Siva Rammurty and B.S.Manoj [2011],"Ad hoc wireless networks architectures and protocols".

2. John Jubin and Janet D.Tornow[January 1987], the DARPA Packet Radio Network Protocols." Proceedings of the IEEE”, 75(1):2132.

3. P. Jacquet and T. Clausen, "Optimized Link State Routing Protocol", IETF Internet Draft, draft-ietf-manet-olsr-11.txt, July 2003.

4. D.B. Johnson, D.A. Maltz, and J. Broch, "DSR: The Dynamic Source Routing Protocol for Multi-Hop Wireless Ad Hoc Networks", Ad Hoc Networking, pp. 139-172, 2001.
5. S. Das, C. Perkins and E. Royer, "Ad Hoc On Demand Distance Vector (AODV) Routing", IETF RFC3561, July 2003.

6. J. Schaumann, "Analysis of the Zone Routing Protocol", December 2002.

7. Z. Haas and M. Pearlman, "The zone routing protocol (ZRP) for Ad Hoc networks", IETF Internet Draft, draft-ietf-manet-zone-zrp04.txt, July 2002.

8. Z. Haas, "A New Routing Protocol for the Reconfigurable Wireless Networks", Proceedings of IEEE ICUPC'97, San Diego, CA, pp. 562-566, October 1997

9. QualNet Documentation, "QualNet 5.0 Model Library: Advanced Wireless":

http://www.scalablenetworks.com/products/Qualnet/download.php\# doc 